\title{
A RELAÇÃO ENTRE LINGUAGEM MENTAL E MUNDO FENOMÊNICO NO SISTEMA LÓGICO OCKHAMIANO
}

\author{
[RELATION BETWEEN MENTAL LANGUAGE AND PHENOMENIC WORLD ACROSS THE OCKAMIAN \\ LOGICAL SYSTEM]
}

\author{
Anderson D'Arc Ferreira * \\ Universidade Federal da Paraíba
}

\begin{abstract}
RESUmo: Tomando como ponto de partida o modelo lógico-semântico desenvolvido pelo Venerabilis Inceptor, que instancia a primazia da experiência e do papel epistêmico do indivíduo, o questionamento basilar de nossa presente investigação é apresentado pela seguinte construção: seria possível produzir crenças precisas acerca do meio-ambiente que nos rodeia a partir do aparato cognitivo humano e das formas com as quais o utilizamos? Nossa investigação procurará analisar a relação entre a estrutura do modelo ockhamiano de uma linguagem mental e sua conexão com o mundo extra-mental, relações essas que possibilitariam não somente a produção de conhecimento, mas, também, a produção de crenças, verdadeiras ou errôneas. Especificamente nos deteremos numa proposta investigativa que pretende analisar qual seria a conexão específica, dentro do modelo ockhamiano, entre as estruturas mentais do indivíduo e o mundo fenomênico no qual ele estaria inserido.
\end{abstract}

Palavras-Chave: Linguagem mental; mundo; externalismo; Guilherme de Ockham
ABSTRACT: Starting from the logical-semantic model developed by Venerabilis Inceptor, who highlights the primacy of experience and the epistemic role of the individual, we aim, with this investigation, the following questions: could we possibly to produce accurate beliefs about the environment starting from the human cognitive apparatus and the ways in which we use it? Our investigation will analyze the relationship between the structure of the Ockhamian model of a mental language and its connection with the extra-mental world, in the sense of they would make enable not only the production of knowledge, but also the production of beliefs, both true or missing. Specifically, we will dwell on an investigative proposal that intends to analyze what the specific connection, within the Ockhamian model, would be between the mental structures of the individual and the phenomenal world in which it would be present.

KEYWORDS: mental language; world; externalism; William Ockam

\section{INTRODUÇÃO}

$\mathrm{D}$ esde o início de suas atividades, os homens que se entendiam como amantes do saber propunham-se vários questionamentos sobre o mundo, os homens, as relações entre os homens, os objetos do mundo que nos rodeiam e a forma de acesso da mente humana frente a esses objetos. Com nomenclaturas variadas e conceitos específicos, como o exemplo do termo "espírito" oriundo de contextos

* Doutor em Filosofia, Professor Adjunto do Departamento de Filosofia da Universidade Federal da Paraíba e suas pesquisas centram-se nos estudos relativos à Filosofia Medieval., m@ailto: andersondarc@uai.com.br 
religiosos, os filósofos sempre se questionaram acerca de questões como: 'o que é a mente (alma, espírito)?' e 'O que caracteriza os movimentos e fenômenos pertencentes à mente (alma, espírito)?’

Muitas vezes nos esquecemos de que somos seres humanos e, portanto, somos sujeitos conscientes, que vivem experiências e possuem estados mentais como ouvir, ver, sentir uma dor, ver os olhos da mente, pensar, questionar, etc. Mas algumas dessas aptidões relativas a estados mentais também podem ser vistas em animais - cães, gatos, pássaros -, portanto, eles também teriam vida mental. Mas, efetivamente, o que seria ter uma mente e apresentar atos mentais?

Normalmente quando falamos em Linguagem Mental tendemos a relacionar estados mentais e atos mentais. Mas, quando falamos nesses eventos, o que especificamente queremos dizer, ou melhor, de que forma podemos dizer que o fato de descrever estados mentais tem significado? Qual é o elemento que possibilita a aquisição de significado por parte das descrições de estados mentais? Se a função da linguagem é a comunicação pública, para que seja garantida uma rede de compreensão do que se fala, como poderíamos transformar a descrição de nossos estados mentais em algo significativo? Como sair de uma descrição subjetiva, descrição dos estados mentais que tenho, para compor a ordem descritiva de dados objetivos, o objeto ou o conceito referido por meu estado mental?

Creio que a pergunta fulcral desse nosso trabalho seria algo do tipo: 'como se dá a ligação entre os conceitos, que expressam estados mentais, e os artefatos do mundo extramental?' ou 'Qual é efetivamente a relação entre termos e objetos?'. Uma linguagem mental teria que conjugar uma estrutura inata que fundamentasse a aquisição de uma linguagem convencional, a Linguagem Mental ou Linguagem do Pensamento, além de necessitar determinar de que forma ocorre a construção e a ligação desses símbolos e sua respectiva ostensão frente a artefatos do mundo extra-mental.

Acreditamos que o modelo ockhamiano do século XIV teria uma resposta interessante para as perguntas acima descritas. Passemos, doravante, a investigar a existência dessa possibilidade e, em caso afirmativo, como ela seria possível dentro do sistema lógico de nosso Frade Franciscano.

\section{O diÁlOgo ENTRE OCKHAM E A NECESSIDADE DO MUNDO EXTERNO}

Várias questões relevantes ao meio filosófico hodierno parecem-nos, efetivamente, como uma reconstrução de problemas antigos. Ao nos adentrarmos nas das pesquisas da História da Filosofia, percebemos que tais questões, na realidade, se constituem de problemas filosóficos, ou seja, de problemas que, independentemente de sua época, assolam as indagações humanas. Nesse movimento de questionamentos contemporâneos, um parece fazer ressonância em meus estudos mais recentes acerca da relação ockhamiana entre a linguagem e o mundo. Especificamente, o problema pode ser refletido mediante a seguinte formulação: o aparato cognitivo humano e as formas pelas quais nós o utilizamos constituem-se de uma forma apta a produzir crenças precisas sobre o meio-ambiente que nos rodeia? O que mais fica evidenciado quando nos ocupamos dessa indagação é a pesquisa acerca da possibilidade de que nossas crenças sejam errôneas e das condições para que possamos produzir conhecimento. No presente trabalho tal investigação assume capital importância e se instancia como nosso objeto de investigação.

Segundo Panaccio, em sua tentativa de estabelecer a possibilidade de debate 
entre o modelo ockhamiano e o externalismo, as relações entre a aquisição do conhecimento e o mundo externo à mente do indivíduo são intrínsecas e se constituem, com base no movimento dos Franciscanos do século XIV, de uma necessidade interacional frente à noção de experiência e indivíduo.

No século XIII e XIV existia um princípio que regia várias das investigações do campo lógico e epistemológico. Esse princípio prefigurava a forma com que deveriam ser estabelecidas as relações entre a linguagem e o pensamento. Sua formulação dizia que algo pode ser significado, ou mesmo nomeado, somente como ele é compreendido. Esse princípio chamado por Panaccio de Modistic, teria a seguinte configuração: sicut intelligitur, sic et significatur. Contudo, a quebra dessa noção, que inicialmente foi operacionalizada por Scotus, tem seus horizontes ampliados pelo sistema ockhamiano de tal forma que o significado das palavras expressadas não seria determinado inteiramente pela intelecção dos falantes. A ampliação desenvolvida por Ockham ocorre dentro de seu sistema mediante a teoria da subordinação.

Dentro da teoria ockhamiana da subordinação, subordinatio, as palavras não significam conceitos, mas coisas. Uma palavra significa entes singulares reais. Contudo, apesar de palavras não significarem conceitos, a sua significação não é independente de conceitos. Para o frade franciscano existe uma dependência semântica que ocorre entre as palavras e os conceitos. É justamente essa dependência que prefigura a subordinação. Nas palavras de Ockham:

Eu digo que as palavras faladas são sinais subordinados aos conceitos ou as
intenções da alma não porque no sentido estrito do 'significar' elas significam
sempre os conceitos da alma primeiramente e propriamente. O ponto é mais
propriamente que as palavras faladas estão impostas para significar as coisas
autênticas que são significadas por conceitos da mente [grifo nosso], de modo
que um conceito primaria e naturalmente signifique algo e uma palavra falada
signifique a coisa mesma secundariamente [...] A mesma sorte da relação que eu
reivindiquei prender entre palavras faladas e as impressões ou as intenções ou os
conceitos prendem entre palavras escritas e sons falados1x.

O que essas palavras demonstram é que conceitos significam coisas naturalmente, portanto, são sinais naturais das coisas. Também prefiguram que sons falados, que são convencionais, são subordinados a determinados conceitos e, devido a essa subordinação, eles herdam a significação dos conceitos. É nesse sentido que as palavras e as marcas escritas subordinam-se aos sons falados e delas herdam, em grau subordinado, sua significação. Essa montagem hierárquica da subordinação ockhamiana demonstra que nem sempre ela ocorre na relação entre a palavra falada e o conceito. A ideia que ele pretende desenvolver é a de que um novo signo, quando este estiver subordinado a outro previamente existente, herdará sua significação do signo preexistente, ou seja, ele herdará as características semânticas do signo anterior, seja essa significação qual for.

Contudo, a noção de imposição, impositio, de um signo deve ser corretamente estabelecida. Alguns comentadores ockhamianos, v.g. Bottin e Michon, ao analisarem a impositio a expressam como se a subordinação fosse a relação que se estabelece entre uma linguagem falada de um determinado falante e o conceito que esse falante teria na mente no momento de efetivação dessa linguagem (pronúncia ou elocução). Contudo, cremos que a noção do texto acima citado não nos remete a essa ideia. $O$ que percebemos, efetivamente, é que a subordinação convencional de um novo signo é algo que ocorre no lugar e no momento da imposição do novo signo, portanto, ela não ocorreria na instanciação original do signo convencional, mas ela seria como o elemento que estabelece uma relação da palavra falada com o conceito escolhido pela 
pessoa, imposta num contexto específico $2 x$.

A relação aqui estabelecida insere-se no campo da equivocidade. Nessa linha, uma palavra equivoca seria aquela que, ao longo de sua constituição histórica de aplicação se torna subordinada a diversos conceitos diferentes. Segundo nosso mestre franciscano: "uma palavra falada é equívoca se, em significar coisas diferentes, for um signo subordinado propriamente a diversos conceitos ou intenções da alma" $3 \mathrm{x}$. Dentro desse modelo semântico, portanto, a equivocidade depende da subordinação e a subordinação, por seu turno, depende da imposição. Contudo, de forma inversa, por univocidade devemos entender o movimento de um termo quando esse depende de uma única imposição, mesmo que ele venha a significar muitas coisas de uma única vez. Conforme as palavras de nosso autor, teríamos:

Quem quer que tenha instituído primeiramente o uso do termo 'homem' viu algum homem particular e inventou o termo para significar esse homem e cada substância como ele [...] Mas mesmo que signifique indiferente muitos homens, o 'homem' não é equivoco, porque significando indiferentemente muitos homens é um signo subordinado a apenas um conceito e não a muitos $4 \mathrm{x}$. [grifos nossos]

Aqui temos vários elementos interessantes e extremamente pertinentes à nossa investigação. O mais significativo, no nosso ponto de vista, refere-se à expressão 'Quem quer que tenha instituído primeiramente o uso do termo'. Nosso grifo demonstra que a intenção clara de Ockham é referenciar o movimento da imposição original, ou primeira, a qual acontece, no momento da pronúncia da locução ou do termo, na mente do sujeito. É justamente aqui que temos um ponto interessantíssimo de confluência: a abertura para uma relação entre o significado das palavras que um determinado locutor usa e os conceitos que tal locutor tem na mente no momento de pronúncia da locução. Nos termos de nosso autor temos:

[...] desde que as palavras sejam convencionais, palavras faladas meramente absolutas [aproximadamente: o gênero de termos naturais] podem ser impostas a essas coisas das quais nós temos, ou outros têm, tais conceitos $5 \mathrm{x}$.

Mais uma vez as sutilezas das teorizações ockhamianas tornam-se salientes. A passagem acima torna visível a ideia de que os conceitos de algumas palavras que usamos são subordinados ao poder de alguns conceitos que nós não temos, mas que outros sujeitos detêm. No sistema lógico desenvolvido por nosso autor os conceitos simples absolutos são adquiridos normalmente através de um encontro com o indivíduo ou objeto singular. Quando usamos esse conceito, sem o ter adquirido mediante um encontro singular, o que teremos é uma descrição complexa desse conceito. Contudo, essa descrição que temos estará subordinada ao conceito absoluto simples, mesmo que o sujeito do proferimento não tenha esse conceito absoluto simples, mas, somente, uma descrição do mesmo. É nesse sentido que se torna viável, no sistema ockhamiano, o uso de palavras, com aplicação correta e condições de verdade garantidas, sem que se tenha na mente os conceitos dos quais essa palavra extrai a sua significação6x. A estrutura desenvolvida na Ordinatio7x estabelece que o sucesso da imposição estaria no fato de que o conceito ao qual a nova palavra estaria subordinada deve ser determinado de algum modo. Essa determinação garante uma espécie de condição individualizante para o conceito, a qual é realizada pelo sujeito falante, o impositor, mas que não precisa estar presente na mente desse impositor no momento exato de sua imposição. Portanto, o movimento em si guarda a referência de que temos de ter determinações para usarmos a palavra que foi imposta. O ganho está no fato de que o uso da palavra imposta, qual for, deverá estar em conformidade com a imposição determinada. Esse fato sugere que não 
é necessário ao falante, no ato de fala e da imposição, ter o significado na mente para que a palavra cumpra o significado determinado. $\mathrm{O}$ que se prefigura é o uso dentro de uma determinada condição de imposição.

Se quiséssemos ir um pouco mais adiante poderíamos dizer que essa forma de pensamento no qual a significação das palavras não depende essencialmente do que acontece na mente do falante quando esse pronuncia as suas palavras é muito similar ao que foi proposto por Putnam em seus ensaios de 1989. Justamente aqui, devido a essa similaridade entre as proposituras, vemos claramente uma aproximação do modelo ockhamiano com o externalismo linguístico contemporâneo8x.

Entendemos que por detrás dessa ideia de subordinação ockhamiana foi estabelecido, de forma clara, que uma determinada palavra poderia ser introduzida, convencionalmente, na língua, sem uma definição a ser dada ou mesmo sem que a palavra seja localizada semanticamente em relação a outras palavras utilizadas na mesma língua, de qualquer forma. Essa concepção seria como um nascimento definido da palavra dentro de um contexto específico. Portanto, essa noção parece ser um ponto específico que demonstra a possibilidade do debate das teorias ockhamianas frente às noções expressas contemporaneamente pelo externalismo linguístico. Contudo, poderíamos ainda vislumbrar outro elemento: o modelo ockhamiano não se fecha efetivamente nesse tipo de relação; apenas suas teorizações prefiguram outras relações que constituiriam uma espécie de externalismo do conteúdo mental.

No modelo ockhamiano os conceitos mentais são signos naturais. Mas, efetivamente, a pergunta seria acerca da forma com que poderíamos ter e determinar essa significação natural dos conceitos. Alguns elementos deverão ser levados em conta nesse momento, especificamente a noção de atos intuitivos e de conceitos gerais naturais.

Uma distinção faz-se necessária para adentrarmos no modelo ockhamiano, a distinção entre intuição sensível e intuição intelectual. Nas passagens citadas anteriormente, especialmente a o terceiro e quarto parágrafo da presente seção de nossa empresa, especialmente nos grifos que fizemos das palavras de Ockham, encontraremos os conceitos mediante os quais teremos as chaves para efetivarmos a distinção entre intuição sensível e intuição intelectual, a saber, as noções de notitia experimentalis, notitia abstrativa, notitia intuitiva e notitia intellectualis. De momento, cabe ressaltar a distinção entre intuição sensível e intuição intelectual. A primeira é oriunda propriamente da percepção. A segunda refere-se ao ato singular de compreendermos um objeto através do intelecto. O que irá entrar em questão aqui é a pergunta de como o conteúdo de uma compreensão intuitiva seria determinada, ou seja, em outras palavras, o que seria a intuição: intelectual ou perceptiva?

A resposta ockhamiana é a de que o aspecto interno de minha compreensão intuitiva não seria suficiente, ele mesmo, para determinar, de forma única, o objeto de minha intuição particular. Para Ockham, todas as representações mentais, incluindo-se aqui as compreensões intuitivas singulares de nossa mente, são semelhanças aos seus objetos9x. Uma compreensão intuitiva singular é causada somente por uma determinada coisa, e essa coisa, ou esse objeto, é o semelhante da intuição. Essa formulação nos permite inferir que se dois agentes estivessem em situações a que seus estados internos fossem similares, um poderia intuir algo, o outro poderia intuir um 'plus' a esse algo. Se um anjo observasse a mente desses dois agentes ele não veria uma diferença interna entre seus estados mentais, entrementes, esses estados teriam sido causados por objetos distintos. Mais uma vez percebemos a coadunação do modelo ockhamiano frente ao externalismo.

As aproximações, contudo, ampliam-se na medida em que se investigam os 
conceitos naturais gerais. Recordemo-nos de uma passagem da Suma Lógica de Ockham:

Quem quer que tenha instituido primeiramente o uso do termo 'homem' viu algum homem particular e inventou o termo para significar esse homem e cada substância como ele [...] Mas mesmo que signifique indiferente muitos homens, o 'homem' não é equivoco, porque significando indiferentemente muitos homens é um signo subordinado a apenas um conceito e não a muitos $1 \mathrm{x} 0 \mathrm{x}$. [grifos nossos]

Nessa passagem podemos notar o momento da instituição de uma palavra falada, a palavra 'homo', a qual seria formada pela subordinação ao conceito. Cremos que esse movimento pode ser estendido para o que ocorre quando se adquire um conceito geral de forma natural. Para o Venerabilis Inceptor a aquisição de conceitos básicos de espécie, como o é o termo 'homem', pode ser adquirido em um encontro, tendo este boas condições de observação, porém, um encontro somente não seria suficiente para a aquisição de conceitos mais gerais como o termo 'animal'. A formação do conceito 'homem', esse tipo de conceito de gênero natural, na nomenclatura ockhamiana, é chamado de termo 'absoluto'. Ele é um conceito simples não representado na mente por uma definição complexa. Mas se isso ocorre, qual seria o elemento que determinaria seu 'conteúdo'? A resposta aparece de forma imediata, pois, nos referindo a conceitos absolutos simples, o ‘conteúdo' seria a extensão desse conceito. Mas o que determinaria a 'extensão' desse conceito? A resposta ocorre de forma imediata. A extensão dos conceitos absolutos simples é determinada por duas relações, a saber: uma conexão causal e uma similaridade entre as substâncias. Essas relações são exclusivamente externas à mente do agente/locutor uma vez que garante que um mesmo caso intuitivo seja aplicado a cada substância como ele. Mais uma vez a similaridade para com o modelo putniano é enorme. Contudo, cabe salientar uma diferença sutil, mas importante, a saber, o que se aplica a conceitos, e não a palavras, no modelo ockhamiano não é desenvolvido da mesma linha no modelo putniano. Para Ockham os conceitos são similitudes do que quer que eles representem $1 \mathrm{x} 1 \mathrm{x}$, portanto, conceitos são representações semânticas. Essa manobra efetivamente garante a possibilidade de os conceitos cumprirem um de seus papéis, o de permitir a recognição de objetos novos dentro de sua extensão. É justamente nesse ponto que podemos inserir a noção dos conceitos como atos mentais. Nesse sentido os conceitos, enquanto atos mentais, devem ajudar a reconhecer que coisas individuais devem inserir-se dentro de sua extensão e quais não podem sê-lo1x2x.

Averiguemos uma passagem muito interessante do texto ockhamiano, segundo nosso ponto de vista, no qual estão explicitados alguns aspectos relativos à teoria do ato mental dentro das relações a serem estabelecidas entre o objeto do mundo externo, as palavras e os conceitos:

Outra poderia ser a opinião, segundo a qual a paixão da alma é o próprio ato do intelecto. E porque essa opinião me parece ser a mais provável de todas as que estabelecem estarem subjetiva e realmente na alma essas paixões da alma, como verdadeiras qualidades dela, exporei primeiro o modo que me parece mais provável acerca dessa opinião (...). Digo, pois, que quem quer manter essa opinião pode supor que o intelecto, apreendendo uma coisa singular, produz em si mesmo um conhecimento dessa coisa singular, apenas, conhecimento que se chama paixão da alma, capaz por sua natureza de representar a coisa singular. Portanto, assim como, por convenção, a palavra 'Sócrates' representa a coisa que significa de modo que, ao se ouvir a frase 'Sócrates corre' não se concebe que a palavra 'Sócrates', que se ouviu, corre, mas sim a corrida da própria coisa 
significada por ela, também, quem visse ou inteligisse ser afirmada alguma coisa dessa intelecção de alguma coisa singular não conceberia que a própria coisa a que o conhecimento se refere é assim. Logo, como a palavra convencional representa a própria coisa, também a intelecção, por sua natureza, sem convenção alguma, significa a coisa a que se refere. [grifo nosso] Mas, além dessa intelecção da coisa singular, o intelecto forma em si outras intelecções, que não pertencem mais a esta coisa que àquela. Assim como a palavra 'homem' não significa mais Sócrates que Platão e, portanto, sua suposição não é mais de um deles do que o outro, o mesmo se diria de tal intelecção que por ela não se inteligiria mais Sócrates do que Platão ou qualquer outro homem. Coisa igual se deveria dizer de qualquer outra intelecção, pela qual não se inteligisse mais este animal que outros, e assim por diante. Em suma, pois, as próprias intelecções da alma são chamadas paixões da alma e representam por sua natureza as próprias coisas exteriores ou outras coisas na alma, como as palavras representam as coisas por convenção. [grifos nossos] $1 \times 3 x$

Primeiramente comecemos por notar que Ockham considera as expressões conceito, afecções da alma, paixões da alma, intenções da alma e intelecto como sendo expressões sinônimas. Partindo desse esclarecimento inicial podemos ver no texto acima dois pontos em que se aponta um alinhamento entre as teorizações ockhamianas e as teses de cunho externalista $1 \mathrm{x} 4 \mathrm{x}$ e que prefiguram a necessidade do mundo externo para a formulação de intelecções na mente humana. Primeiramente ele remete a noção de intelecção da coisa referida. Em segundo lugar ele coloca as intelecções como sendo oriundas das coisas que estão fora da alma humana. Nesse sentido podemos notar que a teoria semântica do Venerabilis Inceptor nos mostra claramente que as palavras não significam conceitos, elas se referem a coisas.

Em outra passagem notamos essa mesma referenciação das palavras como tendo seu referente em algo fora da alma humana, vejamos: “(...) o conceito e todo o universal é uma qualidade existente subjetivamente na alma, que por sua natureza é como um sinal de uma coisa fora da alma, assim como a palavra é um sinal das coisas pela instituição voluntária"1x $5 x$. Assim, teremos a seguinte afirmação dentro de nosso sistema: "o ato da intelecção incide sobre uma realidade existente extra animan" $1 x 6 x$. Justamente aqui temos uma congruência entre o sistema que afirma uma primeira forma do externalismo, o linguístico, e a segunda forma de externalismo, o do ato mental.

Para entendermos precisamente como um modelo implica outro, dentro do sistema desenvolvido pelo Venerabilis Inceptor, temos que entender a forma de dependência semântica que nosso autor postula. Realmente podemos falar em uma forma de dependência semântica dentro desse sistema. Contudo devemos visualizar que tal dependência semântica acontece das palavras em relação aos conceitos. Essa relação de subordinação é expressa na teoria da subordinação. Entrementes, podemos notar que a formulação de uma espécie de linguagem mental em Ockham inicia elementos que também nos garantem e atestam a união do externalismo linguístico com o externalismo do ato mental $1 \times 7 \mathrm{x}$.

Recordemos aqui algumas das relações semânticas dentro da teoria da subordinação ockhamiana. No sistema do Frade Franciscano a subordinação prefigura uma forma de interação e dependência entre palavras, conceitos e mundo extramental. O texto a seguir é retirado da mais elaborada obra lógica de nosso autor, a saber, a Suma Lógica. Em suas palavras: "O ponto é mais propriamente que as palavras faladas estão impostas para significar as coisas autênticas que são significadas por conceitos da mente, de modo que um conceito primaria e naturalmente signifique algo e uma palavra falada signifique a coisa mesma secundariamente"1x8x. A relação de subordinação, contudo, parece ficar mais clara a partir da seguinte passagem: 
Primeiramente, cumpre saber que se chama intenção da alma algo na alma destinado a significar algo diverso. Assim, como foi dito antes, do modo em que o [termo] escrito é signo secundário com respeito às palavras faladas, porque entre todos os signos convencionalmente instituídos, as palavras faladas têm o primado, assim as palavras faladas são signos secundários daquilo de que as intenções da alma são signos primários. E, por isso, diz Aristóteles que as palavras faladas são 'marcas daquelas coisas que são paixões da alma '. Aquilo, porém, existente na alma, que é o signo da coisa, a partir do qual a proposição mental se compõemao modo em que a proposição vocal se compõe de palavras faladas -, e às vezes chama-se intenção da alma, às vezes similitude da coisa, e Boécio, no Comentário ao Perihermenéias, chama intelecção. Assim, ele pretende que a proposição mental seja composta de intelecções, não certamente de intelecções que são realmente da alma intelectiva, mas de intelecções que são certos signos da alma, significando outras [coisas] e dos quais a proposição mental é composta. Assim, quando quer que alguém profira uma proposição falada, antes forma interiormente uma proposição mental, que não é de idioma algum, tanto que muitos frequentemente formam interiormente proposições que, em razão de defeito do idioma, não sabem expressar. As partes dessas proposições mentais chamam-se conceitos, intenções, similitudes e intelecções $1 \mathrm{x} 9 \mathrm{x}$. (Nosso grifo)

No sistema ockhamiano notamos que existe uma realidade, a linguagem mental. Essa linguagem mental é uma forma de realidade psíquica em que falar e compreender seriam operações que corresponderiam, na mente humana, à associação de sinais sonoros a formas de representações mentais realmente existentes em cada um. A linguagem mental em Ockham é uma teoria acerca da mente humana. Debaixo dessa teoria podemos notar a ideia da subordinação, ou seja, uma estrutura em que poder-se-ia exprimir, através de signos vocais, termos mentais. Nesse sentido a linguagem mental teria a função ou capacidade puramente referencial. Essa estrutura coloca nossos atos mentais em estreita conexão com a linguagem, não com uma forma de psicologismo. Para nosso lógico medieval temos que o ato intelectivo, entendido como um signo de uma coisa singular, é algo de real, mesmo que isso se remeta a uma pura intenção da mente. Como os conceitos, termos mentais, significam de forma natural todas as coisas que significam, eles exprimem, de forma direta, a coisa significada uma vez que são produzidos naturalmente através da interação do objeto com o intelecto. Para Guilherme de Ockham:

O termo concebido é a intenção ou paixão da alma significando ou cosignificando naturalmente algo, capaz de ser parte da proposição mental e de por ela supor. Assim, estes termos concebidos e as proposições compostas por eles são aquelas palavras mentais que Santo Agostinho, no Livro XV do tratado Sobre a Trindade, diz não serem de língua alguma, porque permanecem apenas na mente e não podem ser proferidas ao exterior, embora as palavras faladas, como sinais subordinados a eles, se pronunciem exteriormente $2 \mathrm{x} 0 \mathrm{x}$. [grifo nosso]

Aqui percebemos alguns elementos relevantes que nos permitem pensar certa característica relacional entre as teorizações ockhamianas e o externalismo de conteúdo mental. Para o Príncipe dos Nominalistas os conceitos são semelhanças e tal similaridade conceitual não pode ser pensada como algo que determinaria a extensão do conceito. Um conceito, independentemente do que ele possa representar, não se reduz ao que ele representa. $\mathrm{O}$ conceito determina exatamente o que o conceito representa. $\mathrm{O}$ que determina a extensão do conceito absoluto, como vimos anteriormente, é o objeto que causou o conceito, portanto, a extensão é determinada externalisticamente. Três passagens ser-nos-ão de grande valia nesse ponto. A primeira assim nos relata: “(...) por ora, basta considerar que a intenção [conceito] é algo na alma, que é um signo que 
significa naturalmente algo pelo qual pode supor ou que pode ser parte de uma proposição mental'"2x1x. A segunda assim nos assevera:

(...) a mesma coisa sob um conceito singular é universal e sob um outro conceito é singular. Desse modo é dito que toda a coisa colocada fora da alma é por si singular; e essa coisa singular tem uma aptidão natural para mover o intelecto para concebê-la confusamente e para concebê-la distintamente. E chamo conceito confuso aquele conceito pelo qual o intelecto não distingue esta coisa de outra e, assim, Sócrates move o intelecto a conceber que ele é homem e, por tal conceito, não distingue o intelecto nem discerne Sócrates de Platão2x2x. [grifo nosso]

Por fim, a terceira e última passagem nos afirma:

(...) pode ser dito que por tal inteleç̧ão confusa é que se inteligem as coisas singulares exteriores; assim como, ter uma intelecção confusa do homem não é senão possuir um conhecimento pelo qual não se intelige um homem mais que outro, e contudo por esse conhecimento mais se conhece ou intelige o homem que o burro. Isso não quer dizer senão que esse conhecimento, por algum modo de assimilação, mais se assemelha ao homem que ao burro, se bem que não mais a este homem que àquele $2 \times 3 x$. [grifo nosso]

As passagens aludidas acima, em sua sequencia, colocam o conceito como algo que determina o que ele representa, ou supõe. Aqui, nas afirmações referentes ao mundo extramental e sua relação para com os estados produzidos no intelecto, nota-se que a extensão do conceito é determinada externalisticamente pelo mundo ao entorno do sujeito cognoscente/falante. $\mathrm{O}$ que os conceitos nos prefiguram são apontamentos para a percepção, portanto, para o mundo externo, extramental. Contudo, pelo fato de o conceito estar ligado a um esquema perceptivo, ocorre que tal esquema pode falhar e, nesse sentido, conduzir a mente humana a categorizar algo que ele não é, como, por exemplo, quando olho algo como um boi e ele não seja efetivamente um boi. Esse conjunto de teorizações, portanto, leva Ockham a estabelecer e integrar, dentro dos conceitos absolutos, alguma sorte de esquemas de reconhecimento, sem que esses esquemas sejam, efetivamente, aquilo que determina as extensões desses conceitos. E aqui temos o apontamento fulcral que nos permite pensar em um externalismo de ato mental, a saber, os conceitos simples, apesar de serem determinações oriundas dos procedimentos operacionais da linguagem mental, e, portanto, aspectos introspectivos, somente terão a sua extensão determinada de forma externalística, ou seja, pelo entorno extramental que envolve o sujeito cognoscente.

Contudo, esses não são os únicos indícios de que nosso frade franciscano tivesse desenvolvido teorizações que se aproximam ao externalismo do ato mental. Em um desenvolvimento ocorrido na Ordinatio $2 \mathrm{x} 4 \mathrm{x}$, nosso autor discute a forma com que adquirimos vários conceitos não-absolutos tais como: conceitos sincategoremáticos, conceitos conotativos e conceitos negativos. A sistematização proposta assevera que as apreensões desses conceitos não é algo que ocorre de forma natural e, por isso, são frutos de um movimento executado pela mente na base mesma da representação das palavras. Na passagem supracitada é afirmado que conceitos podem ser impostos ou abstraídos das palavras e que o intelecto impõe a esses conceitos supracitados o ato de significar a mesma coisa que palavras faladas externas significam.

Os postulados que se seguem à passagem supracitada são muito interessantes. Primeiramente observamos que existem duas etapas no processo acima descrito. Num primeiro momento a mente, de forma natural, forma representações mentais das palavras faladas, ou escritas, apenas em contato com objetos do mundo externo à mente. O movimento específico do intelecto, como é referido na passagem da 
Ordinantio, estabelece que o intelecto abstrai os conceitos comuns que poderiam ser dele predicados, ou seja, os conceitos se aplicam às palavras, de tal forma, que um conceito que esteja naturalmente apto a ser predicado de determinado sinal linguístico pertencerá, de forma natural, à sua extensão. Portanto, findo essa primeira etapa, iniciase o segundo movimento. No segundo movimento, conforme aludido anteriormente, o intelecto irá subordinar o conceito que deu a forma verdadeira à palavra àquilo ao qual o referido conceito significa naturalmente. Portanto, como nos casos anteriores relatados a respeito da noção de subordinação, o conceito herdará sua significação da palavra falada. Esse ato é prefigurado no modelo ockhamiano pelo termo "imponere", ou seja, impor uma nova significação àquela que a palavra detinha anteriormente. Esse ato de imposição fará com que o termo não signifique mais de forma natural, mas, efetivamente, se comporte como a palavra, ou seja, ele irá significar o objeto mesmo, e, portanto, essa função garantirá que o termo será fixado em minhas proposições mentais. Esse movimento ocorre tendo em vista que o termo poderia ser predicado de várias ocorrências linguísticas e poderá, agora, mediante seu novo significado, ser predicado dos significados dessas unidades linguísticas.

As possíveis derivações que podemos pensar para essa estrutura são interessantes. Inicialmente cabe ressaltar que o conceito instaurado pela dinâmica descrita é ambíguo, pois apresenta duas significações diferentes. Uma delas seria os moldes da significação natural, ou seja, uma via em que não se pode perder o acordo do sinal com determinada palavra falada, portanto, não se pode perder o elo de ligação entre esses significados, a palavra falada e o sinal. A segunda seria uma espécie de significação instituída na qual os signos significariam por eles mesmos.

Acreditamos, entrementes, que essa ambiguidade desenvolvida por essas duas significações distintas, é o tipo de ambiguidade que ocorre quando a um termo dado é permitido supor em contextos proposicionais diferentes. Contudo, essa forma de ambiguidade é algo com o qual a mente pode lidar e obter sucesso na maioria das vezes. Esse tipo de ambiguidade oriundo da estrutura da linguagem mental é relatada por Ockham da seguinte forma: "a terceira modalidade da equivocação pode ser encontrada em uma proposição puramente mental (...)" $2 \times 5 x$. Existem algumas ambiguidades que são tratadas e examinadas minuciosamente por nosso autor, ambiguidades estas que podem ser qualificadas como sendo do tipo uso/menção, ou seja, elas ocorrem quando o contexto proposicional permite ao mesmo tempo uma suposição pessoal e material. Mas esse caso ocorre, dentro da estrutura da linguagem mental, de forma esporádica. A ambiguidade entre a significação natural de um conceito que possa representar as palavras e a significação a ele instituída não pode ser qualificada, simplesmente, como sendo de uso/menção, embora lhe seja muito similar. Ao que nos parece, a forma com que esses elementos são postulados no sistema ockhamiano teríamos uma espécie de subordinação invertida, ou seja, em vez de se subordinar uma palavra falada a um conceito, o que ocorre é que se subordina um conceito a uma palavra falada. As implicações que poderíamos extrair desse sistema seriam muito interessantes pois instanciariam novas relações entre nossas representações naturais, as representações das palavras que temos e as representações mentais com as quais computamos significados às palavras que consideramos 'verdadeiras' em sua representação natural.

Entendemos que toda essa estrutura nos coloca de forma mais próxima ao externalismo, uma vez que a significação de alguns de nossos conceitos poderiam, em alguns casos, depender da imposição convencional de determinadas palavras oriundas de determinação de outros falantes. Essa 'espécie' de subordinação invertida permitiria estabelecer uma enorme precisão frente aos conceitos utilizados e sua extensão. Essa precisão seria uma enorme contribuição para com os conceitos em sua relação com as 
condições de verdade das proposições mentais, uma vez que tais proposições mentais seriam muito precisas. Contudo, apesar de salvar-se a significação do conceito, essa estrutura reversa deixa em aberto o domínio desse conceito, portanto, a estrutura ockhamiana, ao que me parece até o momento, não daria conta de garantir os dois elementos. Mas independentemente dessa lacuna, entendemos que essa estrutura se coaduna de forma satisfatória a vários elementos adotados por alguns modelos de externalismo de conteúdo mental.

Por mais que o frade franciscano afirme a necessidade de um ato mental ele sempre postulará a necessidade de algo externo ao agente para dar início aos procedimentos que envolvem os atos mentais e, por conseguinte, à linguagem mental. É nesse sentido que devemos entender de que forma Ockham chega a postular que existem representações mentais que se referem necessariamente a coisas externas. Contudo, essas representações acontecem no mesmo nível do conceito, não ao nível das imagens.

\section{CONCLUSÃo}

O que falamos acerca do sistema ockhamiano nos demonstra a amplitude e a complexidade de suas teorizações. Em suas construções pudemos notar alguns elementos fulcrais: uma adesão ao nominalismo, o reconhecimento de que o mundo é composto por seres singulares e o fato de que a experiência é algo necessário para a aquisição do conhecimento. A junção desses três pilares desenvolve um conjunto teórico profícuo e que no fundo tenta dar conta de estabelecer a conexão entre os elementos constituintes do signo proposicional, alicerçados numa estrutura inata da linguagem mental, e os elementos da realidade a que esses signos se referem. A novidade desse modelo ockhamiano é que o emprego da linguagem não pode ocorrer somente no campo das estruturas sintáticas como as bases das construções semânticas, mas, efetivamente, o mundo extramental se compõe de um elemento necessário para a construção do significado natural dos signos desenvolvidos por nosso intelecto. Assim, a estrutura da linguagem mental, como instanciadora dos atos mentais que criam os sinais e seus significados, necessita de algo mais, necessita dos objetos do mundo externo para a criação dos signos subjetivos.

É nesse contexto que devemos entender o papel das teorias da conotação, da subordinação e da suposição ockhamianas. Uma propriedade semântica, para nosso autor, tem como competência o estudo da significação dos termos que se encontram inseridos numa proposição. Nesse sentido podemos observar que o modelo ockhamiano pressupõe uma estrutura que valoriza o papel da experiência na construção dos signos e significados.

Na proposta ockhamiana, é a teoria da significação que tentará dar conta da resposta acerca da relação entre nosso pensamento e o mundo extramental e, nesse sentido, ela poderia ser entendida como uma teoria da referência aos moldes dos sistemas tradicionais. Essa construção possibilita uma relação imediata entre as estruturas da linguagem escrita, oral e mental com os objetos do mundo. Essas relações, se estivessem somente no campo da significação convencional, seriam simplesmente respondidas por nossas estruturas sintáticas. Mas como a relação do nosso intelecto para com a elaboração de signos que remetem a objetos do mundo extramental ocorre de forma natural, é necessário reconhecer que, na criação e aplicação dos signos dentro das proposições os objetos do mundo ocupam algum lugar, tem alguma relevância. 
Apesar de toda a estrutura lógica ockhamiana, qual seria o elemento que possibilitaria às palavras tomarem o lugar das coisas carregando consigo toda a sorte de objetos dos quais podemos estabelecer proposições? A resposta estará na teoria da referência adotada pelo frade franciscano. Quando falamos de alguma coisa, é pela linguagem que nos expressamos e temos acesso ao mundo2x6x. A pergunta acerca da relação existente entre uma expressão e aquilo de que ela ocupa o lugar, respondida por nosso autor, fixa as relações referenciais entre as palavras e as coisas. Assim, o mundo extramental tem um papel definido e necessário nessa estrutura. Necessitamos do mundo, pelo menos em parte, para estabelecermos corretamente as teorias da suposição, conotação, significação e subordinação.

O movimento iniciado por Quine de descrever as teorias da significação e da referência debaixo de conceitos como nomeação, verdade, extensão e denotação assumem grandes rasgos das teorias medievais da significação e da suposição. Daí o surgimento de sistemas que enquadram suas estruturas ao nominalismo, mais especificamente ligado ao nominalismo do século XIV, propriamente o sistema ockhamiano. Todos esses movimentos parecem ressoar as perguntas acerca da relação entre a referência e aquilo de que ela ocupa o lugar ou como ocorre a relação entre as palavras e as coisas. Frege nos alertava que seu conceito Bedeutung dependeria do contexto no qual ele estaria inserido. Ao observarmos essas posturas, estaremos constatando que vários mecanismos utilizados nas teorias da referência do século $\mathrm{XX}$ são similares aos debates travados nos séculos XIII e XIV quando se indagava acerca de quais mecanismos garantiriam que as palavras poderiam ocupar o lugar das coisas na linguagem.

O modelo ockhamiano apresenta um conjunto de regras, mediante a teoria da referência, que garante que um termo não somente tenha um referente, mas que ele seja determinado por um. Suas estruturas que tentavam explicitar a forma com que nosso intelecto trabalha com os universais estabelecem a necessidade de um mundo extramental e a necessidade de contato das estruturas internas de nosso intelecto, a linguagem mental, para que possamos criar signos, estabelecer conceitos e aplicá-los em proposições que vislumbrem condições de verdade. Sua postura nominalista levou-o a reconhecer a necessidade de contato de nosso intelecto com o mundo via a experiência singular. É a estrutura natural da linguagem mental que irá garantir as condições de aplicação do significado para as palavras de línguas convencionais que expressam nossos estados mentais. Na concepção do Príncipe dos Nominalistas cada indivíduo é único e apreende as coisas do mundo de acordo com seu interior, a sua linguagem interior que é constituída no e com o mundo exterior extramental.

\section{REFERÊNCIAS BIBLIOGRÁFICAS}

OCKHAM, Guilherme de. Expositio in librum Perihermenias Aristotelis. In.: Opera Philosophica II. Ed. Gambatese et S. Brown. Cura Instituti Franciscani, Universitatis S. Bonaventurae, ST. Bonaventure: N.Y. 1978.

Summa Logicae. In.: Opera Philosophica I. Ed. Ph. Boehner, G. Gál. E S. Brown. Cura Instituti Franciscani, Universitatis S. Bonaventurae. St. Bonaventurae: N. Y. 1974. Scriptum in Librum Primum Sententiarum. Ordinatio. In.: Opera Theologicae II. Ed.

S. Brown, adlaborante G. Gál. Cura Instituti Franciscani, Universitatis S. Bonaventure, St. Bonaventure: N.Y. 1970.

Scriptum in Librum Primum Sententiarum. Ordinatio. In.: Opera Theologicae II. Ed. S. Brown, adlaborante G. Gál. Cura Instituti Franciscani, Universitatis S. Bonaventure, 
St. Bonaventure: N.Y. 1970.

LEITE JÚNIOR, Pedro. O problema dos Universais - a perspectiva de Boécio, Abelardo e Ockham. Porto Alegre: EDIPUCRS, 2001.

\section{Notas}

1 Cf. OCKHAM, Sum. Log. I, 1, I, p. 7-8.

2 A passagem do texto ockhamiano da Ordinatio I, dist. 2, Q. 4, Op. Theol. II, p. 139-140 mostra esse mesmo elemento da passagem anterior da Sum. Log.. Contudo, sua ênfase é no ato da imposição e na forma de subordinação dos significados.

3 OCKHAM, Sum Log., I, 13, Op. Phil. I, p. 45.

4 Id., p. 124.

5 OCKHAM, Sum. Log., III-2, 29, Op. Phil. I, p. 558

6 A esse respeito Cf. OCKHAM, Ordinatio I, dist. 22, Q. unica.

7 Ibid.

8 No presente estudo não nos ocuparemos em estabelecer um paralelo entre o modelo ockhamiano e as várias matizações do externalismo dentro da filosofia contemporânea. As indicações que aqui inserimos foram explicitadas em nossa tese doutoral, a qual deverá ser consultada para a efetivação dessas possíveis aproximações. No presente trabalho nos atemos somente ao modelo ockhamiano. Precisemos, contudo, o termo externalismo linguístico, ou seja, um conjunto de teorias que buscaria mostrar que o falante, no momento de sua enunciação, depende de alguns elementos externos a ele, elementos que iriam além de suas estruturas internas e o conduziriam a elementos do seu entorno.

9 O experimento ockhamiano acerca dessa noção se similitude, a qual comprova a veia externalista de Ockham, seria a tentativa do anjo de determinar o objeto de minha intuição. A noção ockhamiana pressupõe que um anjo tem acesso à minha mente no momento em que tenho a intuição de um objeto. Contudo, à minha frente, temos dois objetos idênticos. O anjo seria capaz de saber qual dos dois objetos é o que ativou meu sensoriamento, ou seja, qual dos dois provocou a intuição? A resposta ockhamiana é "não". Somente o entorno, o contexto, poderia dar acesso a esse elemento. Portanto, precisamos de algo mais do que simplesmente os atos mentais. Acerca dessa passagem Cf. OCKHAM, Reportatio, II, q. 12-13. Op. Theol. V., p. 287-288.

10 OCKHAM, Sum. Log., I, 43, Op. Phil. I, p. 124.

$11 \mathrm{O}$ modelo ockhamiano acerca dessas relações dos conceitos, descrita numa parte de seus Quodlibeta, permite entender os conceitos efetivamente como atos intelectuais, não como objetos puramente ideais. A esse respeito Cf. OCKHAM, Quodlibeta, IV, 35, Op. Theol. IX, p. 474.

12 Essa noção enfatiza que conceitos têm de representar seus objetos de alguma maneira.

13 Cf. OCKHAM, Expositio in librum Perihermenias Aristotelis, 351, p. 32, 4-352.

14 Por externalismo devemos entender um conjunto de teorias que defendem que o significado ou o conteúdo mental dependem principalmente do mundo, do meio no qual o indivíduo se encontra.

15 Cf. OCKHAM, Scriptum in Librum Primum Sententiarum. Ordinatio. (Distintiones II-III) VIII, 289, 13-15.

16 Cf. LEITE JUNIOR, 2001, p. 145.

17 Por externalismo de ato mental ou conteúdo mental devemos entender certa matização do externalismo que defende a ideia de que o verdadeiro conteúdo que compõe as crenças de um agente não depende unicamente de estados internos desse agente cognoscente, mas, também, de alguns fatores externos à sua mente

18 OCKHAM, Sum. Log. I, 1. p. 7-8.

19 Id., I, 12, 41, p. 28 , p. 28, 8-42.

20 OCKHAM, Sum. Log. I, 1, 19-25, p. 7.

21 Id., I, 12, 40-53, p. 43. 
22 OCKHAM, L. Sent. VII, 227, p. 11, 15-228.

23 OCKHAM, Exp. Peri. 355, 89-95.

24 Cf. OCKHAM, Ordinatio, I, dist. 2, q. 8, Op. Theol., p. 285-286.

25 OCKHAM, Sum. Log. III - 4, 4, Op. Phil. I, p. 763.

26 Essa visão é compartilhada com vários filósofos de língua inglesa do século $\mathrm{XX}$ até nossos dias. Começando com Frege e o problema da conotação e denotação, passando por Russell, Strawson, Davidson, Quine, Fodor, Putnam, Kripke, Kaplan, etc., os problemas que mobilizaram a atenção de Ockham também foram tratados por eles. Obviamente suas teorizações respondem a determinadas perguntas que não foram feitas no tempo de nosso autor, mas isso não significa que suas teorias não possam dar conta de dizer algo aos problemas contemporâneos e, destarte, ter alguma relevância no que dizem. 